\title{
Pleiotropic Effects of GLP-1. Cardiovascular Evidence of Effectiveness
}

\author{
Pedro Pujante Alarcón ${ }^{1}$, Ana Belén Hernández Cascales ${ }^{1}$, Alfonso López Ruiz ${ }^{2}$, \\ María Ángeles Ibañez Gil ${ }^{3}$, Alicia Hernández Torres ${ }^{4}$, María Dolores Hellín Gil ${ }^{1}$
}

${ }^{1}$ Endocrinology and Nutrition Service of the Hospital University Virgen de la Arrixaca, Murcia, Spain; ${ }^{2}$ Pharmaceutical Care
Research at the University of Granada, Granada, Spain; ${ }^{3}$ Health Center Mariano Yago, Yecla, Murcia, Spain; ${ }^{4}$ Infectious Internal
Medicine of the Hospital University Virgen de la Arrixaca, Murcia, Spain.
Email: alfonsolopezruizmail@gmail.com

Received September $8^{\text {th }}, 2013$; revised October $16^{\text {th }}, 2013$; accepted October $29^{\text {th }}, 2013$

Copyright (C) 2013 Pedro Pujante Alarcón et al. This is an open access article distributed under the Creative Commons Attribution License, which permits unrestricted use, distribution, and reproduction in any medium, provided the original work is properly cited.

\begin{abstract}
Patients with diabetes are characterized by the development of cardiovascular complications: nephropathy, retinopathy, neuropathy, ischemia or hypertensive etc. Therefore, the cardiovascular involvement is the leading cause of death in patients with Diabetes Mellitus type 2 (DM2). Despite intensive treatment on classical factors of cardiovascular disease (blood pressure levels, LDL cholesterol, etc.), patients with diabetes have a high number of cardiovascular events and the onset and prognosis of these are related to glycemic control parameters, glycosylated hemoglobin (HbA1c). On the other hand, the question of the cardiovascular protective effect of some hypoglycemic treatments has been raised, asking what he has done to know more accurately about the safety and cardiovascular effects of the treatments we have today. The two most important incretin hormones are GIP (gastric inhibitory polypeptide) and GLP-1 (glucagon-like peptide-1). Treatment based on GLP-1 is a novel weapon in T2DM that achieves a reduction in HbA1c with other metabolic effects: weight loss and extra effect in dyslipidemia and blood pressure. In the last years other beneficial actions such a protector effect against myocardium ischemia and other actions in basals were reported. In this article we will try to explain the evidence of GLP-1 treatments and its cardiovascular effects.
\end{abstract}

Keywords: GLP-1; T2DM; Myocardium Ischemia

\section{Introduction}

The incidence of type 2 diabetes is a health problem now and with future prospects uncertain. It is estimated to reach 300 million diabetic patients in the coming years [1]. Patients with diabetes are characterized by the development of cardiovascular complications: nephropathy, retinopathy, neuropathy, ischemia or hypertensive etc. [2]. Therefore, the cardiovascular involvement is the leading cause of death in patients with Diabetes Mellitus type 2 [3]. Despite intensive treatment on classical factors of cardiovascular disease (blood pressure levels, LDL cholesterol, etc.), patients with diabetes have a high number of cardiovascular events and the onset and prognosis of these are related to glycemic control parameters, glycosylated hemoglobin (HbA1c) [4].

On the other hand, it has raised the question of the cardiovascular protective effect of some hypoglycemic treatments, rosiglitazone, $[5,6]$ asking what he has done to know more accurately about the safety and cardiovascular effects of the treatments we have today.

\section{Incretins}

The incretin effect is known as the amplification of the insulin response that occurs after oral ingestion of glucose in the administration of an equivalent amount intravenously. This effect is responsible for up to $60 \%$ of the increase in insulin secretion after ingesta [7].

Incretins are intestinal peptides original in response to intake. Among its effects include stimulation of insulin production, suppression of glucagon thereby reducing hepatic glucose production and inhibition of $\beta$-cell apoptosis [8]. Nauck et al. [9], showed in 1986 that the incretin effect was decreased in patients with type 2 diabetes because they decrease in the concentrations of GLP-1 
(and GIP), after ingestion. Its efficacy is mediated by its action on GLP-1 receptor abundantly expressed in the gastrointestinal tract but may be present also in pancreatic tissue, lung and stomach, nervous system, heart, vascular smooth muscle cells and macrophages. For this reason, besides the already mentioned hypoglycemic effect, GLP-1 effects are attributed regulation about the appetite, decreased gastric emptying, increased peripheral insulin sensitivity, as well as neuro and cardioprotective effects $[4,10]$

Thus, treatments aimed at acquiring an incretin effect have been for many years an attractive therapeutic target that nowadays is part of our medical arsenal. Also we have drugs GLP-1 analogues resistant to inactivation of the enzyme DPP-4 (liraglutide), incretin mimetics resistant to DPP-4 (exenatide) and inhibitors of the enzyme DPP-4 (vildagliptin, siltagliptin, saxagliptin).

\section{GLP-1 and Cardiovascular Risk Factors}

Exenatide has shown a reduction of about $1 \%$ in $\mathrm{HbAlc}$ in patients without prior treatment or with sulfonylureas and metformin alone or in combination. It also adds a beneficial effect on fasting blood glucose and postprandial glucose [11-14], with a reduction in weight up to 5.3 $\mathrm{kg}$ in those studies for 3 years [15]. Similarly Liraglutide reduces $\mathrm{HbAlc}$ over $1 \%$ in patients with different combinations of antidiabetic orales [16-18] and even compared to glargine insulin [19] with a beneficial effect on weight. In those studies comparing the effect of liraglutide vs. exenatide, liraglutide shows a greater reduction in $\mathrm{HbA} 1 \mathrm{c}(-1.12 \%$ vs. $0.79 \%, \mathrm{P}<0.05)$ with similar effect on weight loss ( $3 \mathrm{~kg}$ approximately) in 26 studies weeks [20].

Furthermore, liraglutide and exenatide have shown a reduction in cardiovascular risk factors including dyslipidemia and blood pressure. In a meta-analysis of 6 studies performed more than 2000 patients exanatide showed a reduction systolic (SBP) without changes in diastolic blood pressure (DBP). This effect could not be explained completely by weight loss [21]. Liraglutide has demonstrated in the 6 studies LEAD a reduction of $2.5 \mathrm{mmHg}$ SBP. This effect has been demonstrated in the first 2 weeks before the weight loss [22]. Regarding the lipid profile exenatide has demonstrated a decrease in the concentration of triglycerides by $12 \%, 5 \%$ total cholesterol, LDL $6 \%$ and increased HDL cholesterol by $24 \%$ in studies conducted at 3 years[15].

In addition to these cardiovascular effects have been reported in animal studies and human in vitro different actions of analogues of GLP-1 on macrophages and monocytes by decreasing their accumulation in atherosclerotic plaques and reducing production of inflammatory mediators such as TNF- $\alpha$ or CD11b expression [23].

\section{GLP-1 in the Cardiovascular System}

Vascular function:

Different studies in healthy patients have been conducted to determine the effect of acute or chronic analogs of GLP-1 in the endothelium. First, the acute treatment has been shown to increase blood flow to endothelium-dependent vascular level in non diabetic patients [24] and in diabetics with stable coronary disease [25]. Moreover chronic treatment with GLP-1 analogs has shown improvement in endothelial function and vasoconstriction in rats diabetes induced with estreptozocine [26]. In addition, some studies suggest that this improvement in endothelial dysfunction provides vasodilation and improved blood flow to areas distal, common site for the development of complications associated with diabetes [4]. One of the potential mechanisms by which GLP-1 analogs affect the vascular tree is due to the reduction of the toxic effect of glucose on the endothelial cell. GLP-1 has been shown to decrease the deleterious effect of advanced glycation products (AGE) in the endotelium [27].

Cardiac function:

Most studies designed to determine the effect of GLP-1 on cardiovascular function have focused on models of ischemia and reperfusion. Studies in vivo and in vitro with cardiomyocytes in mice have shown that after a period of ischemia and subsequent reperfusion, the mice treated with GLP-1 analogs significantly reduce the size of the infarct zone post-ischemia improve cardiac contractility, systolic function and diastolic function [28]. Similar experiments have given similar results in canine models of dilated cardiomyopathy [29] and porks [30]. In humans, a small, non-randomized study in patients, most non-diabetics, who had undergone coronary revascularization after acute myocardial infarction and to which he had been given an infusion of GLP-1 analogs for 72 hours, an improvement in ejection fraction and better left ventricular myocardial contractility had been reported. In this sense Sokos et al. [31] selected 20 patients who underwent aortocoronary bypass and who infused GLP-1 analogues. Observed in the treated group that the use of vasoactive or inoprotic drug was lower and there were fewer arrhythmias. In additional studies, infusion of GLP-1 analogs for 48 hours in patients non-diabetics and heart failure reduced fasting glucose levels and insulin levels increased compared to placebo associated with an increased heart rate and blood pressure but no impact hemodynamics.

The mechanism by which it acts is not clarified. It is thought that the myocardium after ischemia increases glucose uptake. This increase improves glucose oxidation and producing more ATP than from the free fatty acids. In addition to this increased supply of glucose to 
myocardial ischemia occurs a minor ischemic damage. That has been regarded as a cardioprotective effect of the myocardium with consequent smaller necrosis [32] zone. What we do not known if this action is mediated by GLP-1 receptor exclusively or by an intermediate metabolites such GLP-1 (9 - 36), an antagonist receptor have also shown beneficial effect after isquemia [4].

\section{Conclusion}

Therapies based on incretins, GLP-1 have proven to be an effective treatment for glycemic control with very beneficial effects on weight, blood pressure and lipid profile. Moreover, although the results are preliminary, we observe a beneficial effect on associated complications of DM2. The modifications to the atherosclerotic plaques and improving endothelial dysfunction make us foresee a very beneficial effect on cardiovascular disease prevention. On the other hand, with the data in models of ischemic heart disease, and the cardioprotective effect of GLP-1, demonstrated in animal and human experiments, we do consider the possibility of a beneficial effect beyond the treatment of cardiovascular risk factors. However, the data in the treatment in diabetes and heart failure are not as conclusive. In these patients, we must not forget the side effects of current therapies against type 2 diabetes: the water retention of glitazons and insulin or the contraindicated indication of metformin in patients with renal failure. Although larger, prospective, randomized studies are needed in order to determine the safety of GLP-1 analogs in heart failure, we can not discard them when planning the best treatment for this kind of patients.

\section{REFERENCES}

[1] H. King, R. E. Aubert and W. H. Herman, "Global Burden of Diabetes, 1995-2025: Prevalence, Numerical Estimates and Projections," Diabetes Care, Vol. 21, No. 9, 1998, pp. 1414-1431. http://dx.doi.org/10.2337/diacare.21.9.1414

[2] R. S. Clements Jr. and D. S. Bell, "Complications of Diabetes. Prevalence, Detection, Current Treatment and Prognosis," American Journal of Medicine, Vol. 79, No. 5, 1985, pp. 2-7.

http://dx.doi.org/10.1016/0002-9343(85)90503-0

[3] Scandinavian Simvastatin Survival Study Group, "Randomised Trial of Cholesterol Lowering in 4444 Patients with Coronary Heart Disease: The Scandinavian Simvastatin Survival," Lancet, Vol. 344, No. S4, 1994, pp. 13831389.

[4] M. Davidson, "Cardiovascular Effects of Glucagonlike Peptide-1 Agonists," American Journal of Cardiology, Vol. 108, No. 3, 2011, pp. 33B-41B.

http://dx.doi.org/10.1016/j.amjcard.2011.03.046

[5] The ADVANCE Collaborative Group, "Intensive Blood
Glucose Control and Vascular Outcomes in Patients with Type 2 Diabetes," New England Journal of Medicine, Vol. 358, No. 24, 2008, pp. 2560-2572. http://dx.doi.org/10.1056/NEJMoa0802987

[6] J. Hsai, J. D. Otvos, J. E. Rossouw, L. Wu, S. Wassertheil-Smoller, S. L. Hendrix, J. G. Robinson, B. Lund, L. H. Kuller and Women's Health Initiative Research Group, "Lipoprotein Particle Concentrations May Explain the Absence of Coronary Protection in the Women's Health Initiative Hormone Trials," Arteriosclerosis, Thrombosis, and Vascular Biology, Vol. 28, No. 9, 2008, pp. 1666-1671.

http://dx.doi.org/10.1161/ATVBAHA.108.170431

[7] M. J. Perley and D. M. Kipnis, "Plasma Insulin Responses to Oral and Intravenous Glucose: Studies in Normal and Diabetic Subjects," Journal of Clinical Investigation, Vol. 46, No. 12, 1967, pp. 1954-1962. http://dx.doi.org/10.1172/JCI105685

[8] D. J. Drucker, "The Biology of Incretin Hormones," Cell Metabolism, Vol. 3, No. 3, 2006, pp. 153-165. http://dx.doi.org/10.1016/j.cmet.2006.01.004

[9] M. Nauck, F. Stockmann, R. Ebert and W. Creutzfeldt. "Reduced Incretin Effect in Type 2 (Non-Insulin-Dependent) Diabetes," Diabetologia, Vol. 29, No. 1, 1986, pp. 46-52. http://dx.doi.org/10.1007/BF02427280

[10] D. J. Grieve, S. C. Roslyn and B. D. Green, "Emerging Cardiovascular Actions of the Incretin Hormone Glucagon-Like Peptide-1: Potencial Therapeutic Benefits beyond Glycaemic Control?" British Journal of Pharmacology, Vol. 157, No. 8, 2009, pp. 1340-1351. http://dx.doi.org/10.1111/j.1476-5381.2009.00376.x

[11] T. J. Moretto, D. R. Milton, T. D. Ridge, et al., "Efficacy and Tolerability of Exenatide Monotherapy over 24 Weeks in Antidiabetic Drug-Naive Patients with Types 2 Diabetes: A Randomized, Double-Blind, Placebo-Controlled, Parallel-Group Study," Clinical Therapeutics, Vol. 30, 2008, pp. 1448-1460. http://dx.doi.org/10.1016/j.clinthera.2008.08.006

[12] R. A. De Fronzo, R. E. Ratner, J. Han, D. D. Kim, M. S. Fineman and A. D. Baron, "Exenatide (Exendín-4) on Glycemic Control and Weight over 30 Weeks in Methformin-Treated Patients with Type 2 Diabetes," Diabetes Care, Vol. 28, 2005, pp. 1092-1100. http://dx.doi.org/10.2337/diacare.28.5.1092

[13] J. B. Buse, R. R. Henry, J. Han, D. D. Kin, M. S. Fineman and A. D. Baron, "Exenatide-113-Clinical Study Group. Effects of Exenatide (Exendín-4) on Glycemic Control over 30 Weeks in Sulfonylurea-Treated Patients with Type 2 Diabetes," Diabetes Care, Vol. 27, 2004, pp. 2628-2635. http://dx.doi.org/10.2337/diacare.27.11.2628

[14] D. M. Kendall, M. C. Riddele, J. Rosenstock, et al., "Effects of Exenatide (Exendín-4) on Glycemic Control over 30 Weeks in Patients with Type 2 Diabetes Treated with Metformin and Sulfonylurea," Diabetes Care, Vol. 28, No. 5, 2005, pp. 1083-1091. http://dx.doi.org/10.2337/diacare.28.5.1083

[15] D. M. Klonoff, M. C. Riddle, J. Rosenstock, et al., "Exenatide Effects on Diabetes, Obesity Cardiovascular Risk Factors and Hepatic Biomarkers in Patients with 
Type 2 Diabetes Treated for at Least 3 Years," Current Medical Research and Opinion, Vol. 24, 2008, pp. 275286.

[16] A. Garber, R. Henry, R. Ratner, et al., "Liraglutide versus Glimepiride Monotherapy for Type 2 Diabetes (LEAD-3 Mono): A Randomised 52 Weeks, Phase III, DoubleBlind, Paralle-Treatment Trial," Lancet, Vol. 373, No. 9662, 2009, pp. 473-481. http://dx.doi.org/10.2337/diacare.28.5.1083

[17] M. Nauck, A. Frid, K. Hermansen, et al., "Efficacy and Safesty Comparison of Liraglutide, Glimpiride and Placebo All in Combination with Metformin in Type 2 Diabetes," Diabetes Care, Vol. 32, No. 1, 2009, pp. 84-90. http://dx.doi.org/10.2337/dc08-1355

[18] B. Zinman, J. Gerich, J. B. Buse, et al., "Efficacy and Safety of the Human GLP-1 Analog Liraglutide in Combination with Metformin and TZD in Patients with Type 2 Diabetes (LEAD-4-Met + TZD)," Diabetes Care, Vol. 32, 2009, pp. 1224-1230. http://dx.doi.org/10.2337/dc08-2124

[19] D. Russell-Jones, A. Vaag, O. Schmitz, et al., "Liraglutide vs Insulin Glargine and Placebo in Combination with Metformin and Sulphonylurea Therapy in Type 2 Diabetes Mellitus: A Randomised Controlled Trial(LEAD-5 met + SU)," Diabetología, Vol. 52, No. 10, 2009, p. 2046. http://dx.doi.org/10.1007/s00125-009-1472-y

[20] J. Buse, J. Rosenstock, G. Sesti, et al., "A Study of Two Glucagon-Like Peptide-1 Receptor Agonists for the Treatment of Type 2 Diabetes: Liraglutide Once Daily Compared with Exenatide Twice Daily in a Randomised 26 Weeks, Open-Label Trial(LEAD-6)," Lancet, Vol. 374, 2009, pp. 39-47. http://dx.doi.org/10.1016/S0140-6736(09)60659-0

[21] T. Okerso, P. Yan, A. Stonehouse and R. Brodows, "Effects of Exenatide on Systolic Lood Pressure in Subjects with Type 2 Diabetes," American Journal of Hypertension, Vol. 23, No. 3, 2010, pp. 334-339. http://dx.doi.org/10.1038/ajh.2009.245

[22] L. Blonde and D. Russell-Jones, "The Safety and Efficacy of Liraglutide with or without Oral Antidiabetic Drug Therapy in Type 2 Diabetes: An Overview of the LEAD 1-5 Studies," Diabetes, Obesity and Metabolism, Vol. 11, Suppl. 3, 2009, pp. 26-34.

http://dx.doi.org/10.1111/j.1463-1326.2009.01075.x

[23] M. Arakawa, T. Mita, K. Azuma, C. Ebato, H. Goto, T. Nomiyama, Y. Fujitani, T. Horise, R. Kawamori and H. Watada, "Inhibition of Monocyt Adhsion to Endothelial Cells and Attenuation of Atherosclerotic Lesion by a Glucagon-Like Peptide-1 Receptor Agonist, Exendin-4," Diabetes, Vol. 59, No. 4, 2010, pp. 1030-1037. http://dx.doi.org/10.2337/db09-1694

[24] A. Basu, N. Charkoudian, W. Schrage, R. A. Rizza, R. Basu and M. J. Joyner, "Benefial Effects of GLP-1 on Endothelial Function in Humans: Dampening by Gly- buride but Not by Glimepiride," Endocrinology and Metabolism-American Journal of Physiology, Vol. 293, 2005, pp. E1289-E1295.

[25] T. Nyström, M. K. Gutniak, F. Zhan, J. J. Holst, B. Ahrén and A. Sjöholm, "Effects of Glucagon-Like Peptide-1 on Endothelial Function in Type 2 Diabetes Patients with Stable Coronary Artery Disease," Endocrinology and Metabolism-American Journal of Physiology, Vol. 287, 2004, pp. E1209-E1215.

[26] S. Ozyazgan, N. Kutluta, S. Afsar, S. B. Ozdas and A. G. Akkan, "Effect of Glucagon-Like Peptide-1(7-36) and Exendin-4 on the Vascular Reactivity in Streptozotocin/ Nicotinamide-Induced Diabetic Rats," Pharmacology, Vol. 74, No. 3, 2005, pp. 119-126.

[27] Y. Ishibashi, T. Matsui, M. Takeuchi and S. Yamagishis, "Glucagon-Like Peptide-1 (GLP-1) Inhibits Advance Glycation End Product (AGE)-Induced Up-Regulation of VCAM-1 mRNA Levels in Endothelial Cells by Suppressing AGE Receptor (RAGE) Expression," Biochemical and Biophysical Research Communications, Vol. 391, No. 3, 2010, pp. 1405-1408. http://dx.doi.org/10.1016/j.bbrc.2009.12.075

[28] D. P. Sonne, T. Engstrom and M. Treiman, "Protetive Effects of GLP-1 Analogues Exendin-4 and GLP-1 (9-36) Amide against Ischemiareperfusion Injury in Rat Heart," Regulatory Peptides, Vol. 146, No. 1-3, 2008, pp. 243249. http://dx.doi.org/10.1016/j.regpep.2007.10.001

[29] L. A. Nikoladis, D. Elahi, Y. T. Shen and R. P. Shannon, "Active Metabolite of GLP-1 Mediates Myocardial Glucose Uptake and Improve Left Ventricular Performance in Conscious Dogs with Dilated Cariomyopathy," Heart and Circulatory Physiology-American Journal of Physiology, Vol. 289, 2005, pp. H2401-H2408.

[30] L. Timmer, J. P. Henriques, D. P. De Klein, J. H. Devries, H. Kemperman, P. Steendijk, et al., "Exenatide Reduces Infarcts Size and Improves Cardiac Function in a Porcine Model of Ischemia and Reperfusion Injury," Journal of the American College of Cardiology, Vol. 53, No. 6, 2009, pp. 501-510. http://dx.doi.org/10.1016/j.jacc.2008.10.033

[31] G. G. Sokos, H. Bolukoglu, J. German, T. Hentosz, G. J. Magovern, T. D. Maher, D. A. Dean, S. H. Bailey, G. Marrone, D. H. Benckart, D. Elaine and R. P. Shannon, "Effect of Glucagon-Like Peptide-1 (GLP1) on Glycemic Control and Left Ventricular Function in Patients Undergoing Coronary Artery Bypass Grafting," American Journal of Cardiology, 2007, pp. 824-829.

[32] M. H. Noyan-Ashraf, M. A. Momen, K. Ban, A. M. Sadi, Y. Q. Zhou, A. M. Riazi, L. L. Baggio, R. M. Henkelman, M. Husain and D. J. Drucker, "GLP-1R Agonist Liraglutide Activates Cytoprotective Pathways and Improves Outcomes after Experimental Myocardial Infaction in Mice," Diabetes, Vol. 58, No. 4, 2009, pp. 975-983. http://dx.doi.org/10.2337/db08-1193 